\title{
TEM Study on the Additive-Manufactured AISi10Mg
}

\author{
Wenhui Zhu, Jon Hangas, Yang Li, Yang Huo, Eric Poczatek and Mei Li
}

Ford Motor Company, Dearborn, Michigan, United States

Additive manufacturing is a low-cost solution for the flexible production of customized products in the automotive industry, especially for low volume production, without significantly increasing the lead time when compared to traditional manufacturing processes [1]. Among various technologies of additive manufacturing for metals, Laser Powder Bed Fusion (LPBF) is one of the most promising ways for the fabrication of metallic components with complex structures while maintaining a high standard for performance [2]. Aluminum alloys have been used extensively on vehicles for light-weighting and ultimately improving fuel efficiency. The additive manufacturing of aluminum alloys has been difficult because of their high reflectivity, high thermal conductivity, high susceptibility to oxidation, as well as poor flowability due to the low density of aluminum powders [3]. The limited understanding of the correlation between process conditions and microstructure features of different length scales makes the fabrication even more challenging since the mechanical properties of the alloy are dominated by the microstructure features. Among them, process induced formation of various types of defects $[4,5]$ and ultrafine subgranular Si precipitates in Al-Si eutectics [6, 7] have drawn extensive research interest in the recent years. A couple of typical defects are lack-of-fusion, which is aptly named, and keyhole, which is a deep and narrow vapor cavity in the shape of keyhole caused by the evaporation of elements [8]. However, most previous studies focus on exploring the role of process parameters in the formation of either of these two microstructure features, while the intertwining between them is usually overlooked. In fact, altered process parameters could lead to a simultaneous change in the formation of both defects and subgranular microstructure, which should be comprehensively considered for process optimization and material modeling. To bridge this gap, we present the microstructural study by transmission electron microscopy (TEM) on one typical aluminum alloy, AlSi10Mg, built with different parameters to intentionally generate certain types of defects.

Two types of defects, lack-of-fusion and with keyholes, were prepared by varying the scanning speed of the laser beam during LPBF. Small bulk samples were taken from the $\mathrm{x}-\mathrm{y}$ plane (beam scanning plane) and the $\mathrm{z}$ plane (perpendicular to the beam scanning plane) from each type of sample. These samples were ground and polished from both sides into a thin foil with a thickness of around $100 \mu \mathrm{m}$. Then they were punched into $\Phi 3 \mathrm{~mm}$ discs, dimpled to about $50 \mu \mathrm{m}$, and ion milled until perforation. Each specimen was examined using Thermofisher Talos F200X TEM operated at $200 \mathrm{kV}$. STEM images and EDS results were acquired for the comparison of the microstructures of the alloys with the two features, from $\mathrm{x}-\mathrm{y}$ and z planes, respectively.

The subgranular morphologies of the specimens were taken in the same zone axis for comparison, as shown in Figure 1. There were tiny voids along the rough cell boundaries in the samples with lack-offusion feature; while for the one with keyholes, precipitates of $\mathrm{Si}$ (determined by the $\mathrm{Z}$ contrast) were also shown up at the cell boundaries but with finer traces. When viewing at $\mathrm{x}-\mathrm{y}$ planes, both types of alloys showed the classic honeycomb structure of the cell boundaries with similar size of cells. The morphologies at $\mathrm{z}$ planes showed both elongated cells (shown in Figure $1 \mathrm{~b}$ and 1d), together with the honeycomb structure. This is caused by the repeated thermal impact by melting and solidification when layers were building up during the LPBF process. 
Figure 2 shows the STEM-EDS mapping results of the alloys. In samples displaying a lack-of-fusion, the relatively big Si precipitates at the cell boundaries were discontinuous, with the eutectic Al-Si with the fine alternate layers of $\mathrm{Al}$ and $\mathrm{Si}$. For the one with keyholes, the cell boundaries were characterized by fine and continuous Si precipitates. Such difference could possibly be explained by the change in temperature gradient resulting from the difference in energy density at different scan speeds. There were traces of Si scattered inside the cells for both conditions. The element distributions were consistent no matter it was $\mathrm{x}-\mathrm{y}$ or $\mathrm{z}$ plane. The size of the cells of the alloy lacking fusion appeared bigger than that with keyholes. The results indicate the simultaneous change of subgranular microstructure and morphology of defects in LPBF AlSi10Mg has been induced by different process parameters, which need to be considered in the process optimization and microstructure-informed material modeling for such materials.
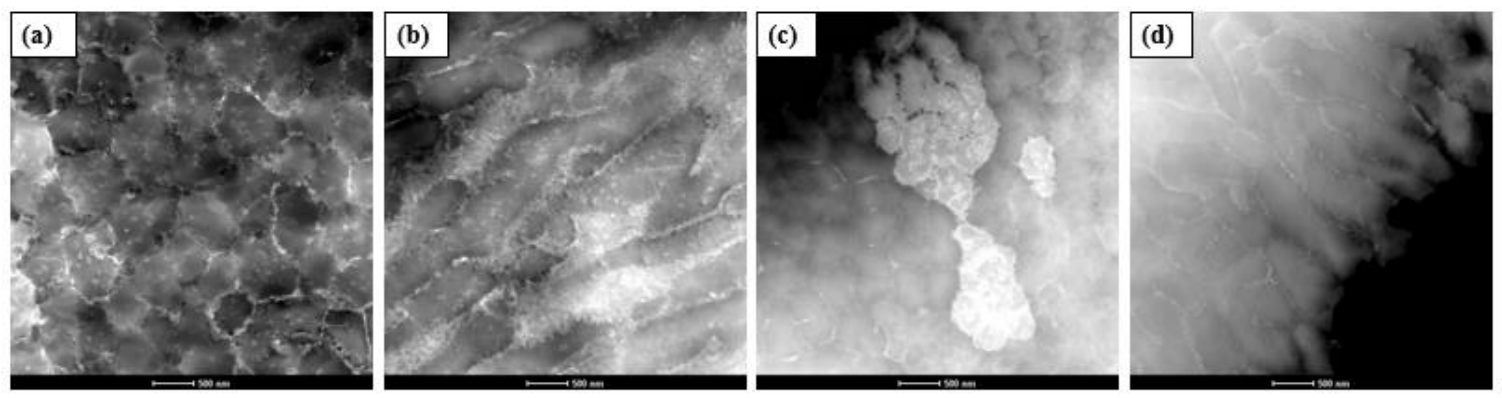

Figure 1. The STEM images of AlSi10Mg at different conditions (a) lack of fusion, $x-y$ plane, (b) lack of fusion, z plane, (c) keyholes, $\mathrm{x}-\mathrm{y}$ plane, (d) keyholes, $\mathrm{z}$ plane. The scale bar is $500 \mathrm{~nm}$. 

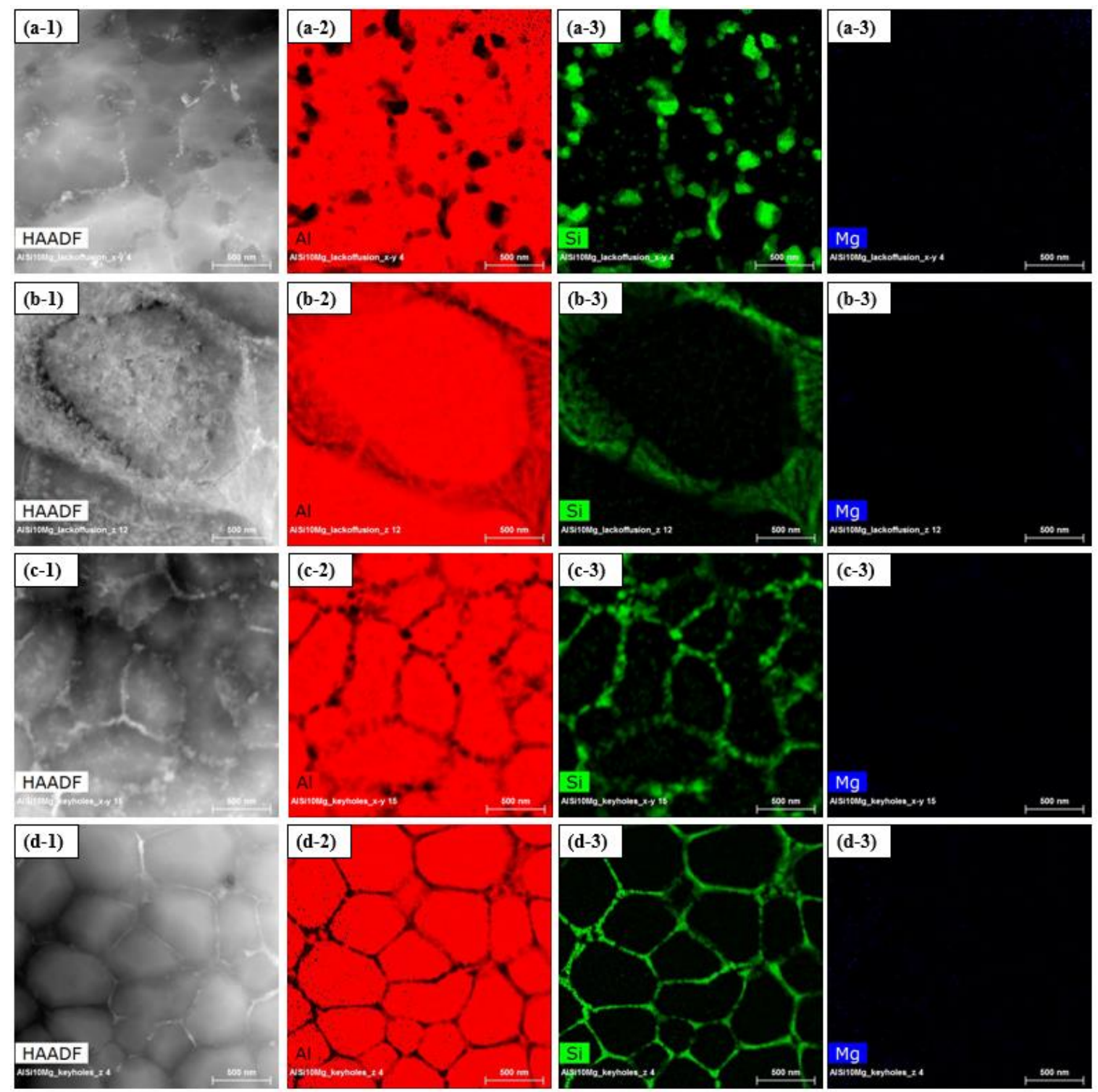

Figure 2. STEM-EDS mapping of AlSi10Mg (a-1 to a-3) lack of fusion, $x-y$ plane, (b-1 to b-3) lack of fusion, z plane, (c-1 to c-3) keyholes, $\mathrm{x}-\mathrm{y}$ plane, (d-1 to d-3) keyholes, z plane. The scale bar is $500 \mathrm{~nm}$.

\section{References}

[1] S. G. Sarvankar and S. N. Yewale, “Additive Manufacturing in Automotive Industry,” Int. J. Res. Aeronaut. Mech. Eng., vol. 7, no. 4, pp. 1-10, 2019.

[2] J. Zhang, B. Song, Q. Wei, D. Bourell, and Y. Shi, "A review of selective laser melting of aluminum alloys: Processing, microstructure, property and developing trends," J. Mater. Sci. Technol., vol. 35, no. 2, pp. 270-284, 2019.

[3] D. D. Gu, W. Meiners, K. Wissenbach, and R. Poprawe, "Laser additive manufacturing of metallic components: materials, processes and mechanisms," Int. Mater. Rev., vol. 57, no. 3, pp. 133-164, 2012.

[4] N. T. Aboulkhair, N. M. Everitt, I. Ashcroft, and C. Tuck, "Reducing porosity in A1Si10Mg parts processed by selective laser melting," Addit. Manuf., vol. 1-4, pp. 77-86, 2014, doi: https://doi.org/10.1016/j.addma.2014.08.001. 
[5] K. V. Yang et al., "Porosity formation mechanisms and fatigue response in Al-Si-Mg alloys made by selective laser melting," Mater. Sci. Eng. A, vol. 712, pp. 166-174, 2018, doi: https://doi.org/10.1016/j.msea.2017.11.078.

[6] N. Takata, H. Kodaira, K. Sekizawa, A. Suzuki, and M. Kobashi, "Change in microstructure of selectively laser melted AlSi10Mg alloy with heat treatments," Mater. Sci. Eng. A, vol. 704, pp. 218-228, 2017, doi: https://doi.org/10.1016/j.msea.2017.08.029.

[7] A. Hadadzadeh, B. S. Amirkhiz, A. Odeshi, J. Li, and M. Mohammadi, "Role of hierarchical microstructure of additively manufactured AlSi10Mg on dynamic loading behavior," Addit. Manuf., vol. 28, pp. 1-13, 2019, doi: https://doi.org/10.1016/j.addma.2019.04.012.

[8] R. Rai, J. W. Elmer, T. A. Palmer, and T. DebRoy, "Heat transfer and fluid flow during keyhole mode laser welding of tantalum, Ti-6Al-4V, 304L stainless steel and vanadium," J. Phys. Appl. Phys., vol. 40, no. 18, pp. 5753-5766, Aug. 2007, doi: 10.1088/0022-3727/40/18/037. 